\title{
OCCUPATIONAL HEALTH HAZARDS OF LIVESTOCK WORKERS IN PAKISTAN
}

\author{
Moin Iqbal $^{1}$, Najamullah Baig ${ }^{2}$, Tayyab Rathore $^{3}$, Farah Yousuf $^{4}$
}

\author{
${ }^{1}$ Veterinary Epidemiologist,Field Epidemiology \& Disease Surveillance Division,National Institute of Health \\ Islamabad \\ ${ }^{2}$ Senior Scientific Officer, Field Epidemiology \& Disease Surveillance Division, National Institute of Health Islamabad \\ ${ }^{3}$ Disease Surveillance Office, Field Epidemiology \& Disease Surveillance Division, National Institute of Health \\ Islamabad \\ ${ }^{4}$ Senior Scientific Officer, Allergy Center, National Institute of Health Islamabad \\ Correspondence: Moin Iqbal, Email: drmoiniqbal@gmail.com
}

\begin{abstract}
One third of the world's population is engaged in agriculture sector that makes it the second largest source of employment worldwide including the female population. In developing countries, the agriculture holds $44 \%$ of employment share. While agriculture sector in South Asia employs $40 \%$ of the people. Livestock workers have to be in close contact with animals and different types of the machinery resulting in high risks of accidents and occupational hazards/ diseases. Environmental factors are also not optimal. Ergonomic difficulties are common i.e. bad working postures, repetitive movements and forceful exertions. A National Occupational Safety and Health Council could be established to protect the health of working folk by legislation and its implementation throughout the country.
\end{abstract}

Keywords: Occupational health, hazards, livestock, agriculture

\section{Introduction}

A worker is an asset to a nation, by all means. Their hard work renders progress and development to any nation. According to WHO (2007) workers contribute to half of the global population. The word 'worker' recounts the efforts of an individual that results in the achievement of a certain task that he/she has been assigned. Their contribution to the social and economic welfare of any country calls for effective measures and interventions to promote and maintain their health at and around the workplace. This narrative revolves around the theme of health hazards that the workers are exposed to, in their daily occupational routine but especially the livestock sector of Pakistan.

\section{Problem Statement}

Although the word 'hazard' itself speak for what it entails yet according to Organization for Economic Cooperation and Development( OECD), "Occupational health hazards are hazards of exposure to pollution, noise and vibrations in the working environment (1)". Comparatively, Myers provides a more comprehensive understanding of the term in relation to the livestock sector. According to him Occupational hazards in livestock sector can be classified into three categories: (2)

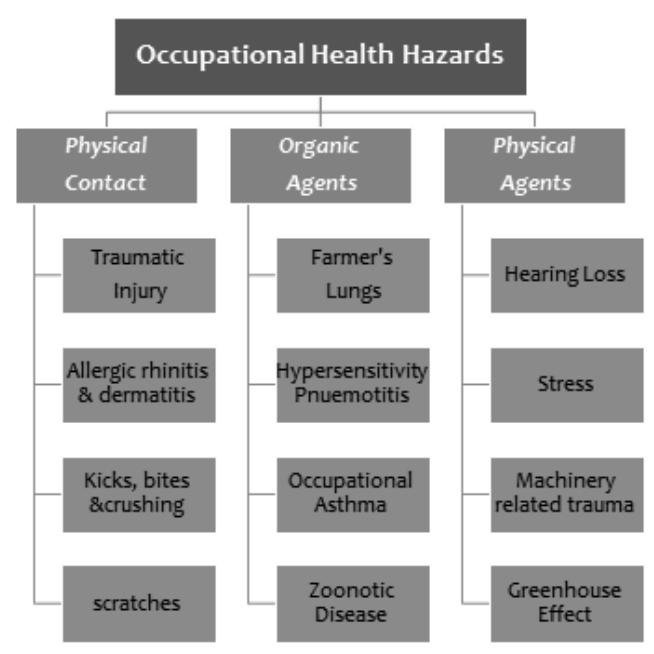

Figure 1: categories of health hazards (2)

Figure 1 depicts the explanation of the term occupational health hazards in livestock workers, as Myers (2015), holds it.

- Physical Contact bears those health hazards that are prone to be afflicted in case of touching the source of hazard. For instance: A farm animal may be acting violent for any reason and in reaction it may kick, bite or crush the worker working with it.

- Organic Agent sare present in innumerable quantity at a livestock farm in the form of agriculture dust 
(feathers, dander, and micro-organisms) \& inorganic dust (Crystalline Silica). With ease, do they make their path to human beings via zoonotic diseases and cause life threatening illness.

- Physical Agents become hazard for the livestock workers as they directly or indirectly use the heavy farm tools and machineries. Tractors contribute to a grave number of fatal injuries, at farm, occurring in the developed countries. Hearing impairment and musculoskeletal disorders are a few serious hazards to name.

\section{Global and Local Scenario}

According to the findings of International Labour Organization (ILO), annually over 2.2 million people give their lives up pertaining to the work related accident or illness. And yearly, more than $\mathbf{2 7 0}$ million workers bear non-fatal work related traumas while 160 million become vulnerable to work pertinent illness (3). A study conducted in USA about 0.6 million employees died owing to work pertinent fatalities and diseases (4). Thus, the occupational health hazards that the agricultural workers are exposed to demand serious attention as well. The livestock sector comes under the umbrella of agriculture sector which employs a billion workers around the world making every 1 in 3 , to be associated with agriculture sector (5).

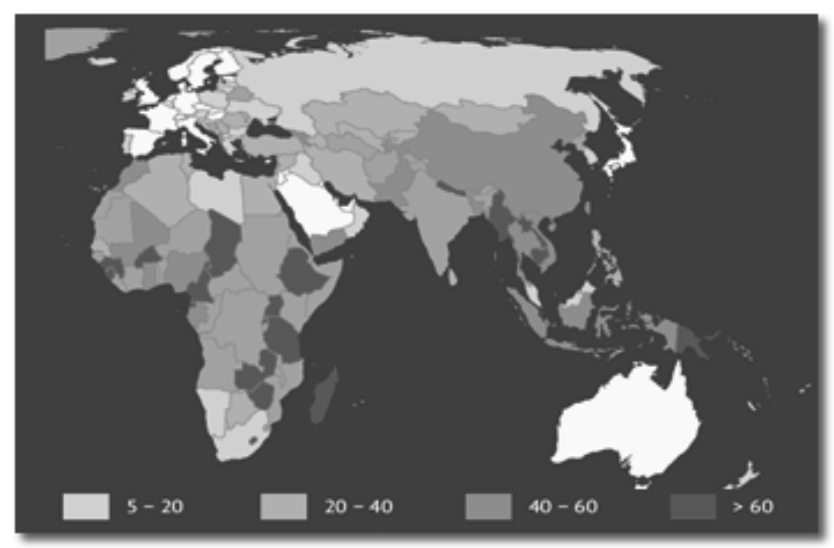

Figure 2: Global Scenario 2010: Agriculture sector share of total employment $\%$ wise. (2)

Statistically, $1 / 3$ rd of the world's population is engaged in agriculture sector that reciprocally makes it the second largest source of employment worldwide. Figure 2 ascertains the data from ILO's report regarding the shared scenario. The black ring secerns Asia Pacific region with high number of employment in some countries as much as $>60$. However, Pakistan covers $40-60 \%$ of employment from agriculture sector (ILO, 2015). Agriculture sector holds importance for females as well; for females of the developing countries are mostly employed in agriculture sector. So are the children. Sadly, this sector contributes to $70 \%$ i.e. approx. 129 million of child labour that unduly exposes children to the occupational dangers of this sector (6).

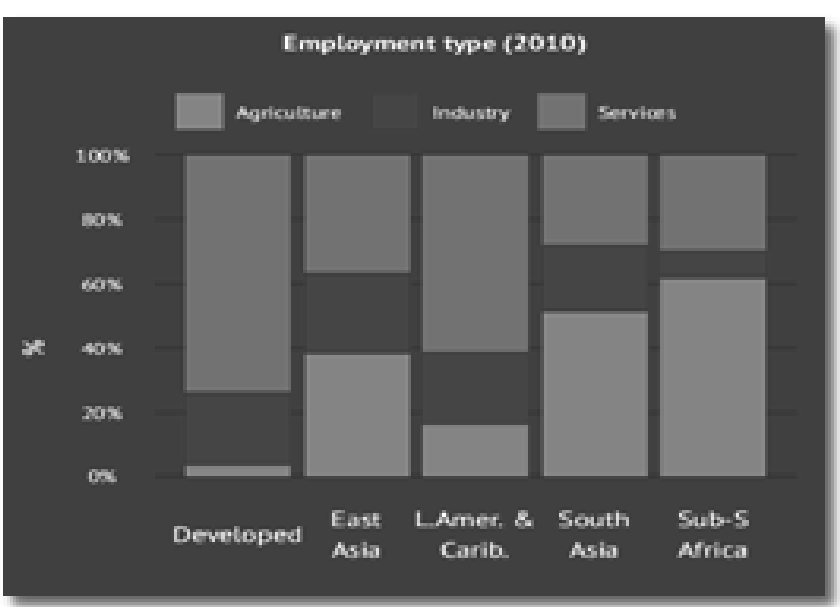

Figure 3: Share of agriculture as per employment type (2).

These facts paint a somber picture of health concerns for the livestock workers for agricultural countries like Pakistan where agriculture holds $44 \%$ of employment share (7). In developing countries employment share of agriculture is major among other jobs. So share the facts from FAO's (2015) report. Approx. 60\% of workers are engaged in livestock sector from Sub Saharan Africa while South Asia employs $40 \%$ and above individuals in the said sector. And approximately $40 \%$ of the people of East Asia opt for agriculture sector as their source of employment. Thus agriculture workers are in dire need of formation and enforcement of legislative laws that not only speak of their rights but also implement them which is sadly not the case.

\section{Occupational Hazards in Livestock sector}

Thinking of working at a livestock farm may seem an innocuous and cushy job but the hazards are real. In the first place the livestock workers have to remain in close contact with animals and then come seemingly humble farm activities that are not limited to the tasks mentioned in the box below:

Table 1. Occupational hazards in livestock sector

\begin{tabular}{|l|l|}
\hline Jobs related to & Tasks involved \\
\hline Administering & Treatments \\
\hline Silage & Attaching, brushing, carrying, cutting \& etc. \\
\hline Maintaining & $\begin{array}{l}\text { Equipment, records, machinery, animals' } \\
\text { health, feeding habits etc. }\end{array}$ \\
\hline Equipment & $\begin{array}{l}\text { Milking, mixing, operating, maintaining } \\
\text { General tasks }\end{array}$ \\
$\begin{array}{l}\text { Pulling, pushing, removing, animal care. } \\
\text { repairing, scraping, shoveling, milking, } \\
\text { spraying, sterilizing, transporting, washing, } \\
\text { weighting etc. }\end{array}$ \\
\hline
\end{tabular}

Consistent exertion, repetitive and forceful movements, 
bad working postures, absence of required machinery, lack of training are some of the conducing factors to name that increase the risk of occupational hazards for livestock workers. It is not just the machinery and animals that are involved in agriculture sector but plants, products, both indoor and outdoor working scenarios given varied climatic and geographic conditions. On one hand where agriculture sector is highly mechanized and urbanized in developed countries, the developing countries still use manual procedures for menial jobs.

According to ILO the health hazards for any worker should be classified into five major categories i.e. accident hazards, biological hazards, chemical hazards, ergonomic hazards and physical hazards. These categories cover almost every possible source of hazard that an individual can come across on site of work (2). The hazards for livestock workers would also be studied under the same categories.

\section{- $\quad$ Accident Hazards}

An accident hazard refers to an event of unavoidable danger or risk that is usually unpredictable, for instance (9):

o Animal handling may result in severe bruising or crushing injuries, kicks, butting, crushing and workers may be tramped on by the violent animal.

- Slips, trips and falls may become the fate of a worker in case of conducting tasks within and outside the farm particularly when working on stairs or levels above ground, slippery surface \& congested areas.

- Animals and workers both are exposed to concentrated poisonous gases as ammonia, carbon dioxide, hydrogen sulfide \& methane that are emitted from fertilizer during mixing and pumping sessions.

- Suffocation occurs due to less oxygen and high concentration of Carbon dioxide and nitrogen oxide in case of improper ventilation in closed barns and while working in the silos.

\section{- Biological Hazards}

This hazard refers to the threat to life or health of a living being/organism by any biological substance for instance: microorganism, and virus or toxin (10).

o $\quad$ Farmers' lung and other respiratory symptoms appear in case of inhaling mouldy material.

- Diseases as occupational asthma, eye irritation, organic dust toxicity, dermatitis, bronchitis \& chronic obstructive pulmonary disease attack the health of a worker who is exposed to respirable dust entailing particles from animal dust, hay, feed dust, bedding and grain dust.

- The urine, manure and bedding of an already disease animal is the host of many zoonotic diseases for instance: dermatoses, intestinal diseases \& respiratory disorders.

\section{- Chemical Hazards}

A combination of chemicals or any chemical or substance alone that may pose any level of threat to the life or health of a living organism/being lies under the category of chemical hazard (11)

- Ammonia causes eye and nose irritation.

- Hydrogen Sulfide is responsible to cause numbness of sense of smell, head pain, eye pain, eye irritation \& appearing symptoms of nervous system related diseases.

- Disinfecting liquids (formaldehyde, sodium carbonate, sodium hypochlorite \& ammonia) \& their vapors, rinsing and cleaning chemicals on farm cause skin diseases and irritation in respiratory tract.

o Formaldehyde that is a surmised carcinogen is used as an antimicrobial in hatcheries and brooders.

- Silage additives cause respiratory tract and eye infections and irritation.

o $\quad$ Feeling of tipsiness owing to inhaling vapors or smell of pesticides, detergents, solvents and acids.

- Cytotoxic agents cause systematic and gastrointestinal problems.

- Latex irritation as result of using latex gloves is quite common in livestock workers that lead to anaphylaxis, dermatitis and asthma.

- $\quad$ Suppressed Immune system due to consistent exposure to dust in the farm tends to cause atopic asthma, rhino pharyngitis, extrinsic allergic alveolitis and hypersensitivity pneumonitis.

\section{" Ergonomic Hazards}

Workplace conditions that pose the risk of injury to the musculoskeletal system of the worker for instance: vibration, temperature Forceful movements, improper/unprofessional methods and postures of working (12)

o Bad working postures invite back ache and other musculoskeletal problems.

o Consistent movements and forceful efforts in lifting bales, feed bags, transportation and slacking of silage, dumping manure manually and other such efforts.

o Improper arrangement of light or less than required lightening cause discomfort results in less efficiency and enhances risk of working accidents.

" Physical Hazards:

A harm that could be inflicted without manually touching the source of hazard for instance: noise, pressure, height (13)

o Presence of machinery on farm as milking equipment, tractors, mills and mixers and then animals could expose a worker to high levels of 
noise.

o Poor ventilation system causes respiratory issues due to drafts \& low temperature in cold barns.

o

Enclosed systems for keeping animals causes heat exhaustion, heat induced dermatoses and sun induced dermatoses to the workers.

Learning about the nature of hazards, one would not wonder to see agriculture sector being on top of the list of the most hazardous occupations of Pakistan. As per the statistical data released by Pakistan Bureau of Statistics (14) about injuries/disease by industry division in 20142015, agriculture sector covered as much as $48 \%$ of injuries and diseases that affected the lives of the workers of this sector. Construction being a seemingly more hazardous occupation covered only $16.3 \%$ of the space on the pie chart. Manufacturing secured $15.9 \%$ of space while wholesale and retail trade cumulated only $7.1 \%$ (figure 4).The data about occupational injuries/disease by industry division in Sindh also showed no different situation (figure 5). Agriculture sector yet remained on top with $63 \%$ of the injuries/disease worrying agriculture workers (14).

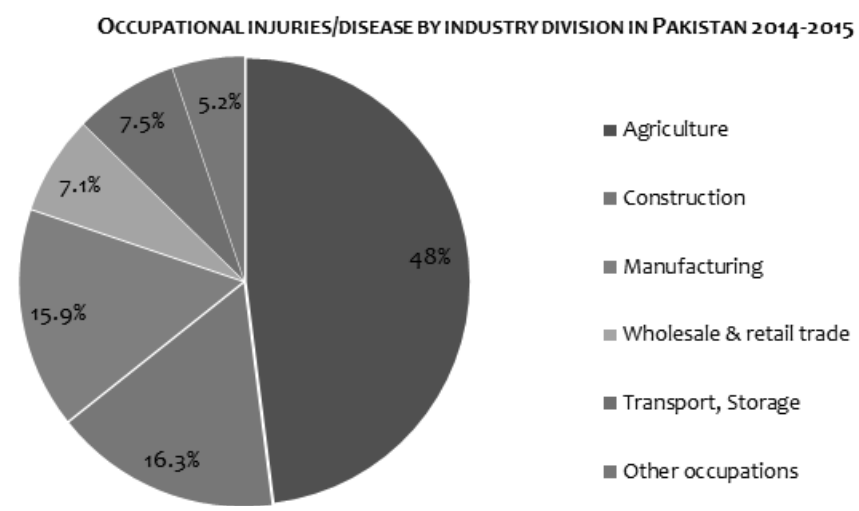

Figure 4. Occupational injuries/diseases by industry division in Pakistan (2014-2015).Source: PBS, Pakistan Labour Force Survey 2014-15 (14)

OCCUPATIONAL INJURIES/DISEASE BY INDUSTRY DIVISION IN SINDH 2014-2015
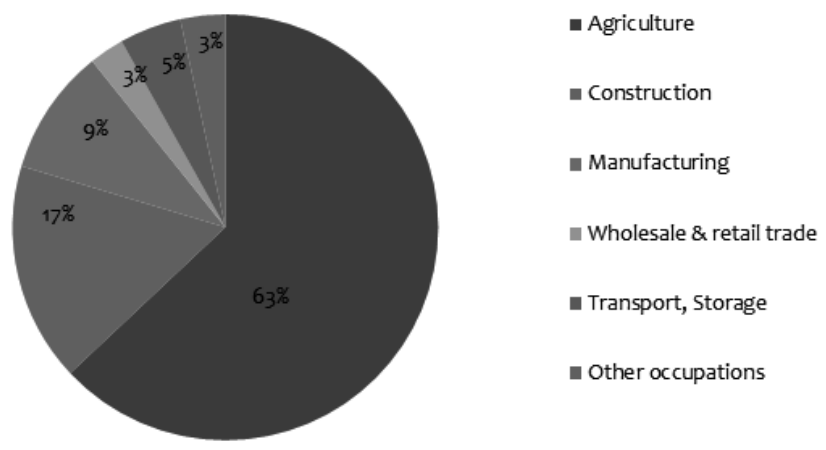

Figure 5. Occupational Injuries/diseases by industry division in Sindh (2014-2015). Source: PBS,
Pakistan Labour Force Survey 2014-15 (14)

Livestock sector: In the eye of Law

Despite of the utmost need of the legislative laws that protect workers' right with perspective of occupational health and safety, no such precise law has yet been established yet that could directly cover the said issues. The main problem is that majority of the laws that are in effect in Pakistan has been inherited from British Colonial Era (15). Those laws were later altered a little over time. The major law that addresses health and safety issues, but that of the industrial workers, is the Factories Act 1934. Third chapter of the law entails acts regarding the health and safety of the workers. Other laws in the book list a few occupations as 'hazardous' and depict particular stipulated conditions of workplace. Those laws would be (16):

- $\quad$ The Hazardous Occupations Rules of 1963

- $\quad$ The Employment of Children Act 1991

- Mines Act 1923

- $\quad$ Social Security Ordinance 1965

- Workmen's Compensation Act 1923

- $\quad$ Shops and Establishments Ordinance 1969

- $\quad$ Sindh Factories Rule 1978

- $\quad$ Dock Labourers'Act 1934 1974

Dock Workers (Regulation of Employment) Act

Analyzing the available labor laws in the constitution emphasize a serious point that the current laws in effect are not in line with the contemporary health and safety standards and practices at present. These laws also do not categorise separate health and safety acts and measures for major hazardous occupations of the country including agriculture, construction, manufacturing and cottage industry. Besides, the aspects of technical standards for safety practices are either superficially ordained or completely elude the coverage of the law. For instance: Occupational Exposure Limits (OEL) are a mandatory part of any labour law in the world, however it is not included in the labour law of Pakistan. There is also a need of a constitutional body that could oversee the matters of occupational health and safety in the light of the law which is a common practice globally. A National Occupational Safety and Health Council could be established that would constitute the required laws and see to it that the laws are enforced equally in each province. Existing laws that could protect the rights of the workers to some extent are not rigorously enforced, a perceivable reason to which could be lack of sentience and professional training. Besides, paucity with regard to the knowledge in areas of occupational health and safety, dearth of research and nonexistence of national institutional body to offer training and advisory service in this area are comparing matter of concern for the policy makers to interpose (17).

Conclusion

Review of the literature at hand confirms the fact that most of the accident nearly $98 \%$, occur due to unsafe, 
improper or unequipped workplace or workplace conditions and unskilled or untrained employees thus accidents can be prevented (18). As it also goes that prevention is better than cure. Webb (1989) too (19), corroborates Muchemedzi and Charamba's (18) claim by ascertaining that employees/workers find in them the conduciveness and likeness towards work and feel emotionally inclined to work where better and safer working conditions are arranged. It induces in workers, a positive sense of worth and leads to higher productivity and reduced absenteeism from work (20). Hence, provision of safety and health rights to optimum level to the workers would only return in favour of the employer in the shape of profit, quality work and satisfaction and commitment of workers form their work.

The recommendation in this section is not only for the employers but employees as well. These preventive measures would assure safety and keep the livestock workers from possible cases of accidents and occupational diseases.

I. It is advised to construct a separate working set up for the livestock workers that is away from the barns of the animals and machine setups. It keeps workers from noise as well as safe, in case of any aggressive attack or activity from animals. Besides, the noise of the tractors, milking pumps, vacuums and other equipment could be very loud. A working set up close to such setting would result in headaches, distress and hearing impairment in worst case scenario. Ear protection is also used while working at a site with unbearable noise. It has been observed in livestock sector of Pakistan that workers do not put on any safety equipment or use safety gears before they begin to work. This act invites hazards. It is the responsibility of the employer to provide such safety gears and equipment's to the workers. For instance, the use of rubber/work gloves would keep livestock workers from getting any dermal allergy or developing skin infection due to consistent exposure to animal dust, organic dust and then a number of chemicals and disinfectants that the workers come in contact with. Non slip rubber boots may seem unnecessary but it prevents slips, trips and falls that could be a serious hazard. Steel toed work boots on farm are also used for the same purpose. Respirators that are commonly called face masks keep workers from inhaling any poisonous chemical vapours or noxious smells that cause nausea, tipsiness or sudden headaches.

II. The idea of using SMV sign in Pakistan is not a very common practice. SMV stands for slow moving vehicle. It is a sign that is placed at a site where a slow moving heavy vehicle is operating. It is visible flashy triangular sign that warns the speedy vehicles about a slow moving vehicle,
III. Another reason that becomes the cause of occupational hazard at an animal farm would be wearing loose or baggy clothing. Male workers must avoid wearing hanging clothes with loose ends that have the risk of getting stuck in the machinery and so must the female workers. Dupatta must be tied around the head as a turban or scarf respecting cultural values and avoiding danger at the same time. The cold or confined barns must have a proper ventilation system. Continuous working with low levels of oxygen in working environment can causes drowsiness, nausea and suffocation. Such condition hampers working quality and increase the risk of accident. Silos, at the same time, should have a proper channel of air so as to avoid meeting the risk of developing mould that causes toxin in feed. And while handling heavy machines, workers usually rely on watch and learn strategy which could be dangerous in any case. Employers must make sure that every time a machine is given to operate to any employee. That employee is properly trained and is aware of the functions of machine, as stated in the manual.

IV. Physical rest is a need of human body. It is said that an overly exhausted worker is equal to an unskilled worker. There should be a proper time designated for the workers to take a break. Working hours must be according to the international standard that is 8 hours a day. Working shifts can be arranged, if required.

V. Workers engaged in any type of work or industry, are their backbone. They cannot be mistreated, firstly being human and secondly because of their efforts to accomplish occupational tasks. It would not be untrue to say that workers are rewarded in form of compensation and benefits they receive but that would not be a mutual benefit. A mutual benefit for both employee and an employer would be the provision of optimum level of safe working environment. Reviewed literature clearly depicts that accidents, hazards and events are preventable. The only need is to ensure such measure that keep mishaps at workplace.

\section{References}

1. Economic Co-operation and Development. Glossary of Statistical Terms. 2001. Available from; https://stats.oecd.org/glossary/ detail.asp? ID=1878

2. International Labour Organization. International hazards datasheets on occupations. 2015. Available from; http://www.ilo.org/safework/ info/publications/WCMS_113135/lang-en/index.htm

3. Pandita, S. Occupational safety and health: 
Concerns in the informal economy, asia monitor resource centre. 2007. Available from; http://www.amrc.org.hk/alu_special/ohs/occupa tional_safety_and_healthconcerns

4. Talaka, J. Asian Pecific newsletter on occupational health and safety. Finnish institute of occupational health: Helsinki, Finland. 2000.

5. Food Agriculture Organization. Labour. 2015. Available from; http://www.fao.org/docrep/ 015/i2490e/i2490e01b.pdf

6. Food Agriculture Organization. Children's work in the livestock sector: Herding and beyond. 2013. Available from; http://www.fao.org/ docrep/017/i3098e/i3098e.pdf

7. Ministry of finance. Population, labour force and employment. 2012. Available from; http://www.finance.gov.pk/survey/chapters_13/ 12-Population.pdf

8. International Labour Organization. International hazard datasheet on occupation: dairy farmer. 2000. Available from; http://www.ilo.org/ wcmsp5/groups/public/---ed_protect/ ---protrav/---safework/documents/publication/ wcms_193145.pdf

9. Erikson. G. Accidents in agriculture- underlying causes. JTI report: agriculture \& industry. 1996; 224; 1-39

10. Gustaffson, B., Lindgrem, G. \&Lundqvist, P.Near Accidents in Agriculture: A survey of Swedish Studies. Swedish J. Agric, Res.1991; 21; 85-93.

11. Awosile, B., Oseni, O.Omoshaba, E. Hazards exposure of workers of animal related occupations in Abeokuta South Western Nigeria. J VetAdv. 2013; 1: 9 - 19.

12. Dosman, J.A., Cockcroft, D. W. (eds.). Principles of health \& safety in agriculture. CR press Inc: Boca Raton, FL. 1989.

13. Centres for DiseaseControl and Prevention. Physical Safety: Animal handling and restraint hazards. 2012. Available from; http://www.cdc.gov/niosh/topics/veterinary/phy sical.html

14. Labour Force Survey of Pakistan, Annual Report. 2014-2015. Available from; http://www.pbs.gov.pk/sites/default/files//Annua I\%20Report\%20of\%20LFS\%202014-15.pdf

15. Hassan, S. A. Health, Safety and Environmental Practices in the construction sector of Pakistan at Department of Earth Sciences, VIllavagen 16, SE-752 36 Uppsala Sweden. 2012; Paper\#. 85.

16. Shafi, M. \& Shafi, P. Labour Code of Pakistan Karachi, Pakistan: Bureau of Labour Publications. Vol. I (15th Ed.) 2005.

17. Pingle, S. Occupational Safety and Health in India: Now and the Future Industrial Health. 2012; 50; 167-171.

18. Muchemedzi, S. and Charamba, L. National health and safety training course. NSSA:
Harare. 2006.

19. Webb, T. How health and safety makes good business sense. 1989. Available from; www.dol.govt.nz/publications/research

20. Oxenburg, M., Marlow, P. and Oxenburg, A. Increasing productivity and profitability through health and safety. The financial returns from a safe working environment. (2nd Ed.). CRC Press: London. 2004.

21. Pakistan Bureau of Statistics. Percentage distribution of employed persons 10 years of age and over suffered occupational injuries/diseases by major industry division, sex and area 2012-2013. 2013a; Available from; http://www.pbs.gov.pk/sites/default/files/Labour \%20Force/publications/lfs_Annual_201213/t29 -pak.pdf

22. World Health Organization. Workers' health: Global plan of action. 2007. Available from; http://www.who.int/occupational_health/WHO_ health_assembly_en_web.pdf

23. Occupational Safety and Health Situation in Sindh, 2014-15. Available from; http:// www.ilo.org/wcmsp5/groups/public/---asia/---robangkok/---iloislamabad/documents/ publication/wcms_566383.pdf. 